\title{
Sloshing Analysis of a Spherical LNG Tanker
}

\author{
Angitha Ann Kuriakose ${ }^{1}$ \\ ${ }^{I}$ Department of Civil Engineering, KMEA Engineering College, Ernakulam, India
}

\begin{abstract}
Natural gas is a convenient, clean and cheap energy source. It has many applications including as fuel for power generation, industrial and home heating and as a chemical feedstock. It is usually transported in the liquid form because of the tremendous reduction in volume, when liquefied $600 \mathrm{~m}^{3}$ of natural gas reduce into $1 \mathrm{~m}^{3} . L N G$ (Liquefied Natural Gas) is carried at $-163^{\circ} \mathrm{C}$ and slightly above atmospheric pressure. All the special features of $L N G$ carriers arise from the need to carry cargo at such a low temperature of $-163^{\circ} \mathrm{C}$. When the tanks are not full, the motion of the ship caused by the wind and waves result in the movement of LNG within the tanks. These movements (sloshing) can severely damage the containment system of the LNG tanker. The present research aims to check the structural stability of a spherical LNG tanker (Kvaerner Moss spherical tank) considering the sloshing effect with different $L N G$ filling levels.
\end{abstract}

Keywords: LNG, Sloshing, LNG tanker, Moss Spherical tank, ANSYS, Sloshing frequency, Sloshing height.

\section{Introduction}

Natural gas is a combustible gas formed naturally in the earth's crest, consisting of about $80 \%$ of methane, the rest being ethane, propane, butane and other inert gases like Nitrogen, Argon, $\mathrm{CO}_{2}$, etc. Natural gas is a convenient, clean and cheap energy source. It has many applications including as fuel for power generation, industrial and home heating and as a chemical feedstock. It is usually transported in the liquid form because of the tremendous reduction in volume, when liquefied $600 \mathrm{~m}^{3}$ of natural gas reduce into $1 \mathrm{~m}^{3}$.

The LNG is transported in ships when the distance between the source and the consumer increases. During the transportation the ship structure will be subjected to external loads like wind loads and wave loads. When the tanks are not full, the motion of the facility, caused by the wind and waves results in the cargo moving within the tanks. These movements are more severe when the tank is partially filled. This occurs when theexcitation frequency is close to the natural frequency of the fluid. This can severely damage the containment system of the LNG tanker. One of the principal design issues for LNG carriers is sloshing as the containment systems have no internal structures to damp out the liquid motion. At present about half of the LNG carriers in the world are the spherical independent tank type. Detailed sloshing studies are required to determine the sloshing characteristics of a new tank design or vessel operating profile.In this worka Moss spherical LNG tank is analyzed and the structural stability is checked considering the sloshing effect. For this Modal and Dynamic analyses of the structure are carried out using ANSYS.

Hale Saglam, Ulrikke Brandt, and Britta Wodecki (2012)[1] explains the different tank types used for transporting LNG in their study. The main purpose of the cargo containment system is to keep the gas below its boiling point and maintaining the adequate insulation. For this purpose it is important to select the appropriate containment system which is also determined by taking into consideration the tanks capability to withstand sloshing loads. Ling Hou, Fangcheng Li and Chunliang (2012)[2] shows that if a tank is subjected to multiple coupled excitations and resonant excitation frequencies, liquid sloshing will become violent and sloshing loads, including impact on the top wall, will be intensified. P. Pal (2009) conducted experimental studies of sloshing of liquid in partially filled container subjected to external excitation. It is found that the slosh characteristics are strongly influenced by the tank geometry, depth of liquid, and the amplitude and frequency of external excitation. Q.W. Ma, Wen Yang Duan, J. Zhou, Xing Zheng, S. Yan (2009)[3] presents a numerical study on the impact pressure in violent sloshing waves in smooth and baffled tanks by using different numerical models. The results indicate that the major peak and the minor peak of pressure in each impact period are mainly caused by the change of momentum of liquid movement. Jang W. Kim, Kunho Kim, Peter S. Kim and Yung S. Shin (2005)[4] presented numerical approach to evaluate the coupling effect on the sloshing load in their study. The motion of liquid cargo inside a LNG tank is solved by a finite-element method. It was concluded that the coupling between the motion of liquid cargo and ship motion not only affect the ship motion but also changes the impact pressure on the containment system.

The structure is modeled and analyzed in softwares CATIA and ANSYS. The tank selected for the work is Kvaerner Moss spherical tank. Material of the tank is taken as Al 5083. The structure is then modeledwith LNG levels of $20 \%, 50 \%, 70 \%$, and $90 \%$. From the modal analysis of the structure it is able to know whether the structure is safe or not. If the frequency obtained due to external excitation matches the natural frequency of the fluid, resonance will occur and the structure will be collapsed. From the dynamic 
analysis, the maximum sloshing height is obtained. Also the filling level at which the maximum sloshing occurs is found out.

\subsection{Modeling}

\section{Modeling and Analysis of The Moss Spherical LNG Tank}

The structure is first modeled with $90 \%, 70 \%, 60 \%, 50 \%$ and $20 \%$ filling of LNG. CATIA (Computer Aided Three Dimensional Interactive Application) was used for modeling the tank. Since the structure is axisymmetric only quarter portion of the tank is modeled. As per IGC 2008 dimensions of the tank are fixed.

- Diameter of the tank $\quad=40.36 \mathrm{~m}$

- Thickness of the tank $\quad=105 \mathrm{~mm}$

In ANSYS the elements used for the analysis are SHELL 63 and FLUID 80 for the tank and LNG. Meshed model of the tank with $50 \%$ filling of LNG is shown in Fig.1. The material properties of Al 5083 and LNG are provided in TABLE 1 and TABLE 2 respectively.

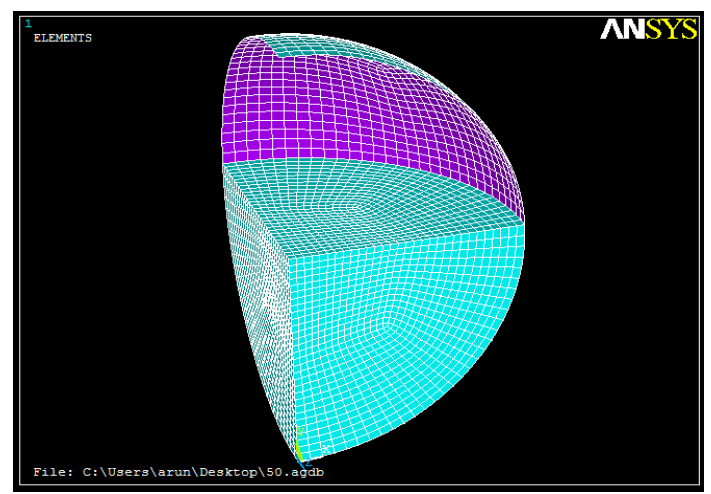

Fig.1: Meshed model of the $50 \%$ filled tank

Table1: Material properties of Al5083

\begin{tabular}{|c|c|}
\hline Material Properties & Values \\
\hline Young's Modulus $\left(\mathrm{N} / \mathrm{m}^{2}\right)$ & $71 \times 10^{9}$ \\
\hline Poisson's ratio, $\mu$ & 0.34 \\
\hline Mass density, $\rho\left(\mathrm{kg} / \mathrm{m}^{3}\right)$ & 2690 \\
\hline
\end{tabular}

Table 2: Material properties of LNG

\begin{tabular}{|c|c|}
\hline Material Properties & Values \\
\hline Specific gravity & 0.45 \\
\hline Density $\left(\mathrm{kg} / \mathrm{m}^{3}\right)$ & 450 \\
\hline Bulk Modulus $\left(\mathrm{N} / \mathrm{m}^{2}\right)$ & $0.848 \times 10^{9}$ \\
\hline
\end{tabular}

\subsection{Boundary Conditions}

The boundary condition provided is Simply Supported at top, bottom and equator of the sphere. Since the structure is axisymmetric, Symmetric boundary condition has to be provided in ANSYS.

\subsection{Loads}

The loads considered for the analyses are wind load and wave load. Forces exerted on the structure by wind depend up on the size and shape of structural members in the path of the wind and the speed at which the wind is blowing. Wind force can be calculated using the equation,

$$
\mathrm{F}=\frac{1}{2} \rho \mathrm{CAV}^{2}
$$

Where,

$$
\begin{aligned}
\rho & =\text { Density of air } \\
\mathrm{A} & =\text { Area of body } \\
\mathrm{V} & =\text { Wind speed } \\
\mathrm{C} & =\text { Dimensionless force coefficient } \\
\text { Take, } \quad \rho & =2.38 \times 10^{-3} \mathrm{slug} / \mathrm{ft}^{3}
\end{aligned}
$$

According to ABS (American Bureau of Shipping),

Maximum Wind speed on LNG tanker $\quad=5 \mathrm{~km} / \mathrm{hr}$.

Force coefficient, c

$=0.5$ (API; 1980).

The wind force obtained

$$
=3028.012 \mathrm{~N}=0.59 \mathrm{~N} / \mathrm{m}^{2}
$$


The effect of wave load is provided as acceleration in ANSYS. The acceleration value provided is $0.45 \mathrm{~m} / \mathrm{sec}^{2}$ in vertical direction.

\subsection{Analysis of Al 5083 spherical LNG tank}

Modal and Dynamic analyses of the Al 5083 spherical tank is done. For checking the structural stability of the tank, Modal analysis of the tank is conducted in ANSYS. In order to get the maximum sloshing height of the LNG, dynamic analysis is done. Early studies show that the maximum sloshing occurs when a tank is partially filled. So by analysing the structure dynamically, this condition for a spherical tank is checked.

\subsubsection{Modal Analysis:}

Modal analysis is used to determine a structure's vibration characteristics, i.e.,natural frequencies and mode shapes. By using the ANSYS software Modalanalysis is done for the Al 5083 spherical tank. From the analysis, the excitation frequencies and the mode shapes at each LNG filling level are obtained. Also the natural frequencies of the LNG at different levels are calculated manually. Thenatural period of the fluid is given by the equation,

$$
\mathrm{T}=\frac{2 \pi}{\sqrt{\mathrm{g} \frac{\pi}{1_{\text {sh }}} \tanh \left(\frac{\pi \mathrm{h}_{\text {fill }}}{1_{\text {sh }}}\right)}}
$$

Where,

$$
\mathrm{h}_{\text {fill }}=\text { LNG fill level }
$$

$1_{\mathrm{sh}} \quad=$ Sloshing length

From this equation we will get the natural frequencies of the fluid at different fill levels. If the excitation frequency obtained from ANSYS matches the natural frequency of the fluid, then resonance occurs. This will leads to the collapse of the structure. This phenomenon is more severe when the tank is partially filled.

\subsubsection{Dynamic Analysis:}

The next objective is to find out the maximum sloshing height of the tank and to check the LNG level at which it is occurred. For this the structure is analysed dynamically. By doing dynamic analysis, the sloshing height at each fill level is obtained. The maximum sloshing height value in each fill level of LNG is taken and is plotted against the percentage fill level of LNG. From the graph, the critical filling level of the LNG is obtained.

\section{Results And Discussions}

In this work, a Moss spherical LNG tank of Al 5083 is modeled at $90 \%, 70 \%, 60 \%, 50 \%$ and $20 \%$ fill level of LNG. After that modal and dynamic analyses were conducted for the tank. From modal analysis frequency values due to external excitation are obtained. It is then compared with natural frequency of the LNG, and checked the stability of the structure. From dynamic analysis the result obtained is sloshing height which is the free surface displacement of LNG.

\subsection{Modal Analysis}

From modal analysis, the frequency due to external excitation is obtained. The frequencies obtained for the analysis of LNG are given in Table 3. Also mode shapes are shown in Figures 2, 3 and 4.

From the table it is clear that, the natural frequency of the LNG and the frequency due to external excitation do not match. The resonance phenomenon occurs only if the natural frequency matches the frequency due to excitation. But here it will not happen since the values do not match. So the dimension taken for the designing of the tank is safe.

Therefore from the above done Modal analysis, the second objective of the thesis to check the structural stability has completed. As a conclusion for the above results, it can be said that, the structure is safe since the resonance phenomenon is not occurred. Also the tank dimensions considered are safe.

Table 3: Frequencies at different fill level

\begin{tabular}{|c|c|c|}
\hline Percentage fill & Natural frequency & Excitation frequency \\
\hline 20 & 0.0160 & 0.0043 \\
\hline 50 & 0.0211 & 0.0027 \\
\hline 60 & 0.0216 & 0.0024 \\
\hline 70 & 0.0218 & 0.0023 \\
\hline 90 & 0.0220 & 0.0023 \\
\hline
\end{tabular}




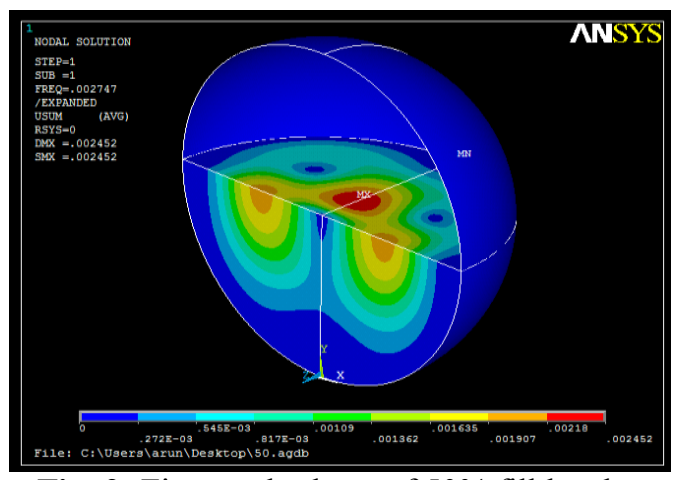

Fig. 2: First mode shape of 50\% fill level

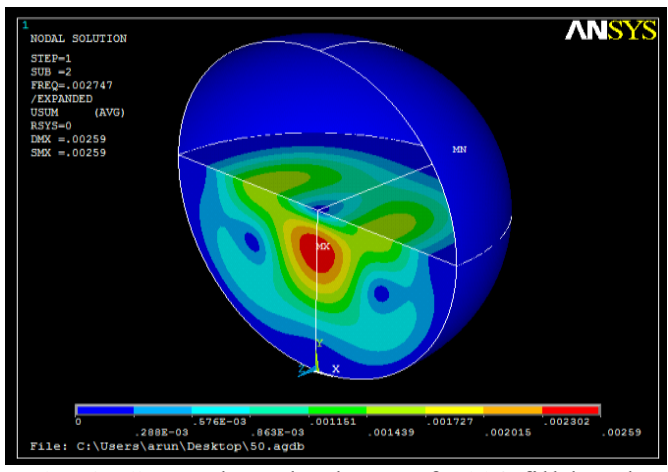

Fig. 3: Second mode shape of $50 \%$ fill level

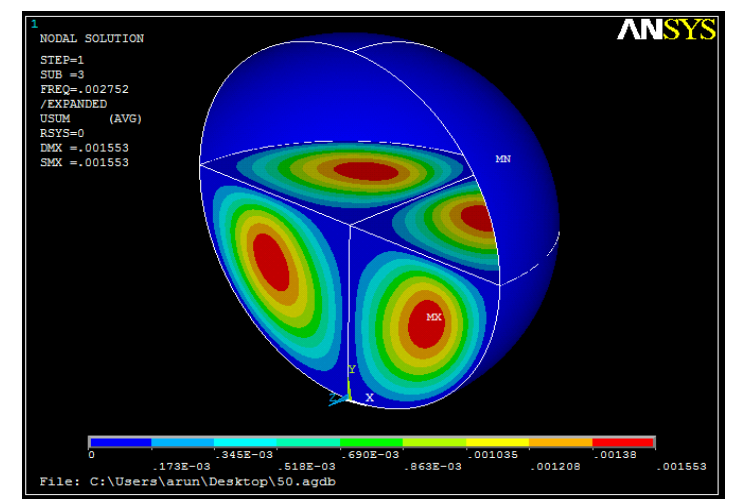

Fig. 4: Third mode shape of $50 \%$ fill level

\subsection{Dynamic Analysis}

The Dynamic analysis is conducted for finding the maximum sloshing height and the LNG level of maximum sloshing is observed. Early studies shows, that the sloshing is maximum for a tank at the partial filling of level. Therefore dynamic analysis has to be done in order to obtain the maximum sloshing height and to check the level at which maximum sloshing occurs in the case of a spherical tank.

\subsubsection{Sloshing height}

Sloshing height is the height of the LNG displaced from the free surface level. The sloshing height obtained at each fill level up to a time of 50seconds with 10 seconds interval is given in the Table 4 . The graph showing sloshing height of the LNG at different fill levels up to a time of 50 seconds is plotted. It is shown in Figure 9. The time interval taken is 10 seconds. The height is increasing with the time. It is also observed that the $50 \%$ fill level has got the maximum sloshing.

In the Table 4, the maximum sloshing heights obtained at each filling level of LNG is provided. The maximum is at $50 \%$ filling level. The result obtained is $0.84 \mathrm{~m}$ height, i.e., the fluid displaces $0.84 \mathrm{~m}$ from the free surface when the external excitation occurs. Therefore from the results obtained it is confirmed that the sloshing phenomenon is severe at a partially filled tank. But from the previous results obtained, it is clear that the tank dimensions taken are safe in withstanding the effect even the maximum sloshing occurs in a partially filled tank.

Table 4: Sloshing heights at different fill levels up to 50 seconds

\begin{tabular}{|c|c|c|c|c|c|}
\hline \multirow{2}{*}{$\begin{array}{c}\text { Time } \\
\text { (Seconds) }\end{array}$} & \multicolumn{5}{|c|}{ Percentage fill level(\%) } \\
\cline { 2 - 6 } & $\mathbf{2 0}$ & $\mathbf{5 0}$ & $\mathbf{6 0}$ & $\mathbf{7 0}$ & $\mathbf{9 0}$ \\
\hline 10 & 0.00725 & 0.167 & 0.02 & 0.016 & 0.006 \\
\hline 20 & 0.0145 & 0.335 & 0.04 & 0.03 & 0.012 \\
\hline 30 & 0.0217 & 0.503 & 0.063 & 0.049 & 0.018 \\
\hline 40 & 0.029 & 0.67 & 0.084 & 0.066 & 0.024 \\
\hline 50 & 0.036 & 0.839 & 0.105 & 0.082 & 0.03 \\
\hline
\end{tabular}

Fig. 5 is the graph showing at which level the maximum sloshing occurs. Fig.6 represents the graph plotted with sloshing height of tank against time. Maximum sloshing occurred at the partial fill level of the spherical tank. But the sloshing will become more severe when the phenomenon called resonance occurs. At 
resonant frequencies, even small periodic driving forces can produce large amplitude oscillations, because the system stores vibration energy. The resonance phenomenon occurs only if the natural frequency of the fluid exceeds the excitation frequency. From the previous results it is clear that this phenomenon will not occurs. So the sloshing is at a safe level. Figure 7 is the sloshing at $50 \%$ filling of LNG.

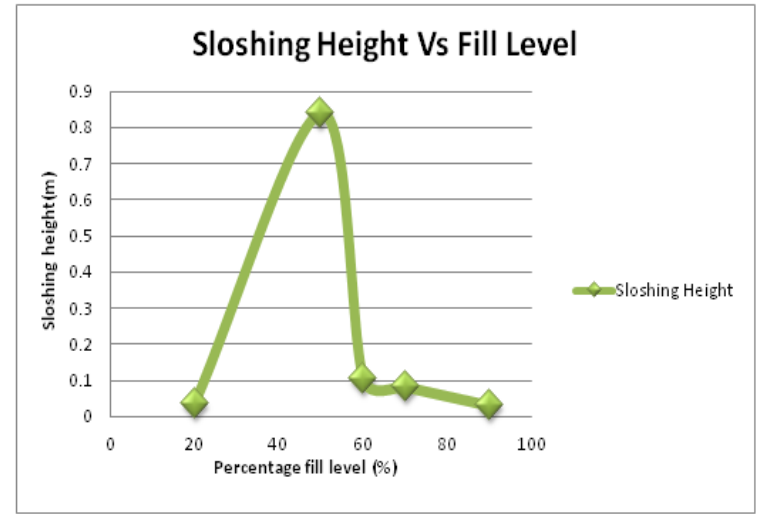

Fig. 5: Maximum sloshing height Vs. Fill level

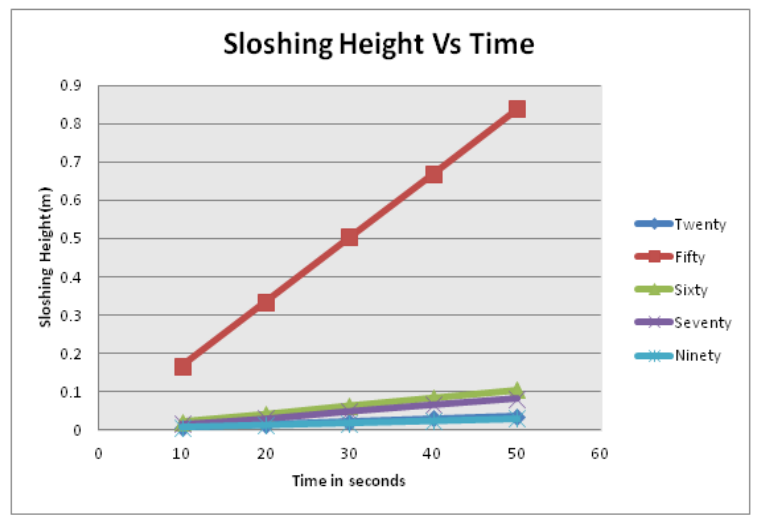

Fig. 6: Sloshing height Vs. time graph

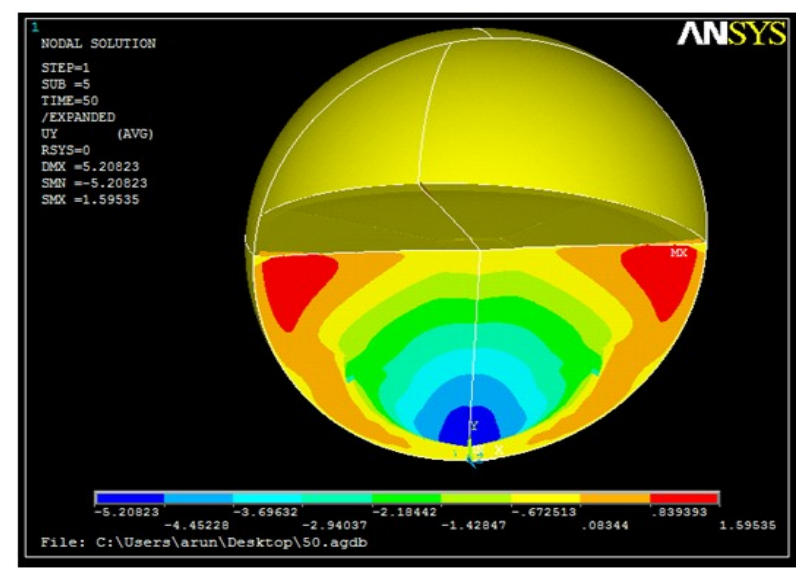

Fig.7: Sloshing height for 50\% fill level at 50 seconds

Table 5: Maximum sloshing heights at each fill level

\begin{tabular}{|c|c|}
\hline Percentage fill level (\%) & Maximum sloshing height (m) \\
\hline 20 & 0.036 \\
\hline 50 & 0.84 \\
\hline 60 & 0.105 \\
\hline 70 & 0.082 \\
\hline 90 & 0.03 \\
\hline
\end{tabular}

\section{Conclusions}

In this research the structural stability of a spherical LNG tank is analysed by considering the sloshing effect due to external excitation. A spherical tank is modelled and analysed at different fill levels of LNG. Modal analysis is done for obtaining the excitation frequency and to check the structural stability of the tank. Finally the structure is analysed dynamically for obtaining the critical sloshing level and the maximum sloshing value of the LNG. The conclusions obtained can be listed as below:

- Excitation frequencies of the tank at different fill levels were compared with the natural frequency of LNG. Since the results did not match, the resonance phenomenonwould not happen. Thus the tank will be safer and the tank dimensions taken were safe.

- The second objective was to find the maximum sloshing height and to check the fill level where the maximum sloshing occurs. For that, sloshing heights at different levels of LNG were found out. From that, the maximum sloshing value was obtained. 
- It was found that the maximum sloshing occurs at the 50\% fill level of LNG. Therefore the critical sloshing height is at the $50 \%$ fill level. So it is confirmed that the maximum sloshing for a spherical tank occurs at partial filling level.

- Even though the maximum sloshing occurs at the partial fill level, it is clear that the tank is safe from the previous results.

\section{References}

[1] Hale Saglam, Ulrikke Brandt, and Britta Wodecki, LNG Carriers, Marine Structural Engineering, 2012

[2] Ling Hou, Fangcheng Li and Chunliang, A Numerical Study of liquid sloshing in a two-dimensional tank under external excitations, Engineering College, Guangdong Ocean University, Zhanjiang,2012

[3] Q.W. Ma, Wen Yang Duan, J. Zhou, Xing Zheng, S. Yan, Numerical study on impact pressure due to violent sloshing waves, School of Engineering and Mathematical Sciences, City University, London, UK, 2009

[4] Jangh W. Kim, Kunho Kim, Peter S. Kim and Yung S. Shin, Sloshing ship motion coupling effect for the Sloshing Impact Load on the LNG Containment System, American Bureau of Shipping Houston, Texas, USA, 2005

[5] Anders Wadahl ,Per Christiansen, LNG FPSO Based on Spherical Tanks, Offshore Technology Conference,2002

[6] A.J Gavin, Design and construction aspects of containment systems for the carriage of liquefied gases in ships, Lloyds register technical association, 1978-79

[7] A study to obtain verification of liquid natural gas (LNG) tank loading criteria, Ship Structure Committee, 1976

[8] Bernhard Godderidge, Mingyi Tan, Stephen Turnock, Chris Earl, AVerification and Validation Study of the Application of ComputationalFluid Dynamics to the Modelling of Lateral Sloshing, University of Southampton, 2006

[9] H Lee, JW Kim and C Hwang, Dynamic strength analysis for membrane type LNG containment system due to sloshing impact load, American Bureau of Shipping, USA, 2004

[10] John L. Woodward and Robin M. Pitblado, LNG risk basedsafety modeling and consequence analysis, John Wiley \& Sons, Inc., Hoboken, New Jersey, 2010

[11] "Liquefied gas carriers with independent tanks hull structural design and analysis",American Bureau of Shipping, 2014

[12] N.A.Hamlin, Liquid sloshing in cargo tanks, Ship Structure Committee, 1990

[13] Odd M. Faltinsen and Alexander N. Timokha, "Analytically approximate natural sloshing modes for a spherical tank shape",Centre for Shipsand Ocean Structures \& Department of Marine Technology, NorwegianUniversity of Science and Technology, Norway, June 2012

[14] P.Pal, Sloshing of liquid in partially filled container, an experimental study,Department of Civil Engineering, MNNIT Allahabad, India.

[15] http://www.liquefiedgascarrier.com/sloshing.html 